\title{
AVALIAÇÃO DE PROJETOS DE EDUCAÇÃO AMBIENTAL NA LAGOA DA PAMPULHA (MG)
}

Marcos Vinicius M. Ferreira ${ }^{1}$

Resumo: O desenvolvimento das sociedades modernas se deu sob a ideia de que a natureza dispunha de recursos infinitos. Entretanto, a pressão exercida nos ambientes devido ao crescimento populacional e à industrialização fizeram surgir uma nova forma de pensar. Ambientes aquáticos estão sofrendo alteração na qualidade de suas águas devido a vários fatores. A lagoa da Pampulha, em Belo Horizonte, não foge a está regra e passa por um momento de enorme degradação. Neste contexto programas de Educação Ambiental são um caminho a ser seguido na formação de uma nova mentalidade. Dois desses projetos serão alvo de discussão neste artigo, o Pampulha Limpa, cuja atuação perdurou de 2003 a 2009 e o seu sucessor, o Pampulha Viva, que assumiu as ações em 2010. O presente trabalho objetiva discutir as metodologias empregadas nos dois projetos afim de verificar sua eficácia na questão da melhoria da qualidade ambiental da lagoa da Pampulha.

Palavras-chave: Água; Educação Ambiental; Degradação.

${ }^{1}$ Universidade Federal de Minas Gerais - Instituto de Ciências Biológicas. E-mail: marcosviniciusmf@yahoo.com.br 


\section{Histórico e importância da Educação Ambiental}

A evolução do conhecimento científico e suas aplicações tecnológicas propiciaram o surgimento das sociedades modernas, caracterizadas pelo desenvolvimento econômico e pela ideia de que a natureza dispunha de recursos infinitos dos quais o homem desfrutaria a fim de obter cada vez mais comodidade. Entretanto, a pressão exercida sob os recursos naturais pelo aumento significativo da população e pelo consumo exagerado de produtos industrializados, sobretudo após a segunda guerra mundial, fez emergir uma nova mentalidade. A partir daí, percebeu-se que os recursos não eram infinitos e que seu uso incorreto poderia causar problemas econômicos e ambientais no futuro.

A constatação dos fatos históricos que tratam da questão ambiental e principalmente, o atual cenário de descuido com os elementos naturais e com a vida, nos permite afirmar que, para verdadeiramente transformarmos o quadro de crise em que vivemos, a Educação Ambiental se torna um elemento estratégico na formação da ampla consciência crítica das relações sociais que situam a inserção humana na natureza (LOUREIRO, 2006).

A reflexão sobre o conceito de Educação Ambiental, seus objetivos e temas de estudo, nos mostra o caminho da preservação e conservação das áreas naturais e do desenvolvimento dos valores humanos. "No que diz respeito à natureza, é importante a proteção e a preservação do meio natural, de seus recursos hídricos e uma análise crítica das questões ambientais, bem como a busca por uma melhor qualidade de vida" (BUSTOS, 2003, p. 53). Assim, pode-se dizer que a educação ambiental é considerada como uma grande possibilidade de transformação da realidade e da qualidade de vida das populações. Deste modo, propõe-se que a Educação Ambiental seja organizada como uma educação formal e não formal, como um processo continuo e permanente, dirigido prioritariamente às crianças e aos jovens e que tenha caráter interdisciplinar.

De acordo com a Secretária de Meio Ambiente de Minas Gerais (SEMAD, 2012, s/p), "transformar e aprimorar a relação entre os seres humanos e desses com o ambiente deve ser o maior objetivo da Educação Ambiental, lembrando que o termo ambiente é muito mais que o ambiente natural, pois inclui as relações do homem com as instituições sociais, a escola, o ambiente de trabalho, a vizinhança, etc.".

A lagoa da Pampulha em Belo Horizonte, há décadas, tem sido alvo de grande degradação ambiental. O surgimento de projetos de Educação Ambiental tem contribuído para tentar mudar a realidade pela qual a lagoa passa atualmente. Este estudo, portanto, tem como objetivo avaliar a eficácia de dois projetos de Educação Ambiental no envolvimento da população da Bacia Hidrográfica da Pampulha na gestão do reservatório da Pampulha: o "Pampulha Limpa" cuja atuação perdurou de 2003 a 2009 e o seu sucessor, e o "Pampulha Viva", que assumiu as ações em 2010. 


\section{Justificativa}

Devido à ação do homem, a qualidade das águas de muitos ambientes aquáticos está sendo drasticamente alterada. Diversas são as causas dessa degradação, como a destinação incorreta dos esgotos, processo descontrolado de urbanização, a mineração, o desmatamento, a destruição dos ecossistemas naturais e o descarte inadequado de resíduos por parte da população. Estes problemas ocorrem, sobretudo, pela falta de conscientização das pessoas. Portanto, é fundamental que a abordagem sobre a gestão de resíduos em ambientes aquáticos seja reforçada pela Educação Ambiental, que deve ser instrumento de alteração de padrões de comportamento e de valorização do meio ambiente e da bacia. Assim, a implantação de projetos como o Pampulha Limpa e Pampulha Viva tornam-se boas alternativas, pois poderão, através dos processos de mobilização, despertar na população o sentimento de pertencimento em relação à lagoa e desta forma contribuir para a melhoria da qualidade ambiental do reservatório.

Diante disso, a análise da metodologia utilizada nos projetos, bem como a avaliação dos resultados obtidos, tornam-se importantes, pois permitirão, no caso do Pampulha Viva, já que o Pampulha Limpa foi extinto, a sugestão de alterações ou adaptações visando o sucesso das ações, considerando que a função de programas de mobilização e sensibilização é contribuir para a formação de cidadãos críticos e participativos em relação ao meio em que vivem. Além disso, a avaliação nas diferentes etapas dos projetos de Educação Ambiental, ou seja, uma avaliação constante é uma etapa importante e que não deve ser esquecida, pois permite repensar o que não está dando certo, propor nova estruturação visando atingir os objetivos propostos. A avaliação permitirá a compreensão e a reflexão, ampliando assim a produção de conhecimentos sobre o programa.

\section{Método}

A metodologia utilizada na realização deste trabalho se baseou em pesquisa literária e análise de documentos e informações sobre os projetos "Pampulha Limpa" e "Pampulha Viva". No caso do "Pampulha Limpa" foram utilizados dois artigos publicados pelos seus organizadores e que estão disponíveis na internet. Quanto ao "Pampulha Viva", foram utilizados na análise informações fornecidos pela coordenação do projeto, através de entrevista e também por meio de materiais como cartilhas e atas de reuniões.

\section{Lagoa da Pampulha: contextualização}

O projeto de construção da Lagoa da Pampulha foi iniciado em 1936, na administração do então prefeito Otacílio Negrão de Lima, através do represamento do ribeirão Pampulha, e teve como objetivos iniciais 0 amortecimento de volumes de água que poderiam causar enchentes, e também ajudar no abastecimento da capital. Sua inauguração se deu em 1943, na gestão do então prefeito Juscelino Kubitschek, que pretendia transformar a 
cidade em uma grande metrópole e por isso dotou a Lagoa de grande acervo cultural e de lazer no qual pode-se destacar a construção de um conjunto arquitetônico inovador e que marcou a história da Arquitetura e do Urbanismo no Brasil. Nesse conjunto, podemos citar o antigo cassino (hoje Museu de Arte da Pampulha), a famosa Igreja de São Francisco e a Casa do Baile (PINTOCOELHO, 2012).

A orla da lagoa da Pampulha concentra também várias opções de laser, como o Estádio Mineirão, o ginásio Mineirinho, o Jardim Botânico, o Jardim Zoológico, o Parque Ecológico, o Centro de Preparação Equestre da Lagoa e pistas de ciclismo e caminhada.

A Bacia Hidrográfica da Pampulha, (Figura 1), estende-se pelos municípios de Belo Horizonte e Contagem, e é composta por 8 afluentes: Córregos Mergulhão, Tijuco, Ressaca, Sarandi, Água Funda, Braúna, Olhos D’água e AABB. Os córregos Sarandi, Ressaca e Água Funda são os de maior importância, responsáveis pelo aporte de $75 \%$ do abastecimento da Lagoa. A área total é de $97 \mathrm{Km}^{2}$, sendo $42 \mathrm{Km}^{2}$ pertencentes a Belo Horizonte (Portal $\mathrm{PBH}$, http://portalpbh.pbh.gov.br/pbh/ecp/noticia). Saindo da Pampulha, a água cai no Córrego do Onça que por sua vez deságua no Rio das Velhas.

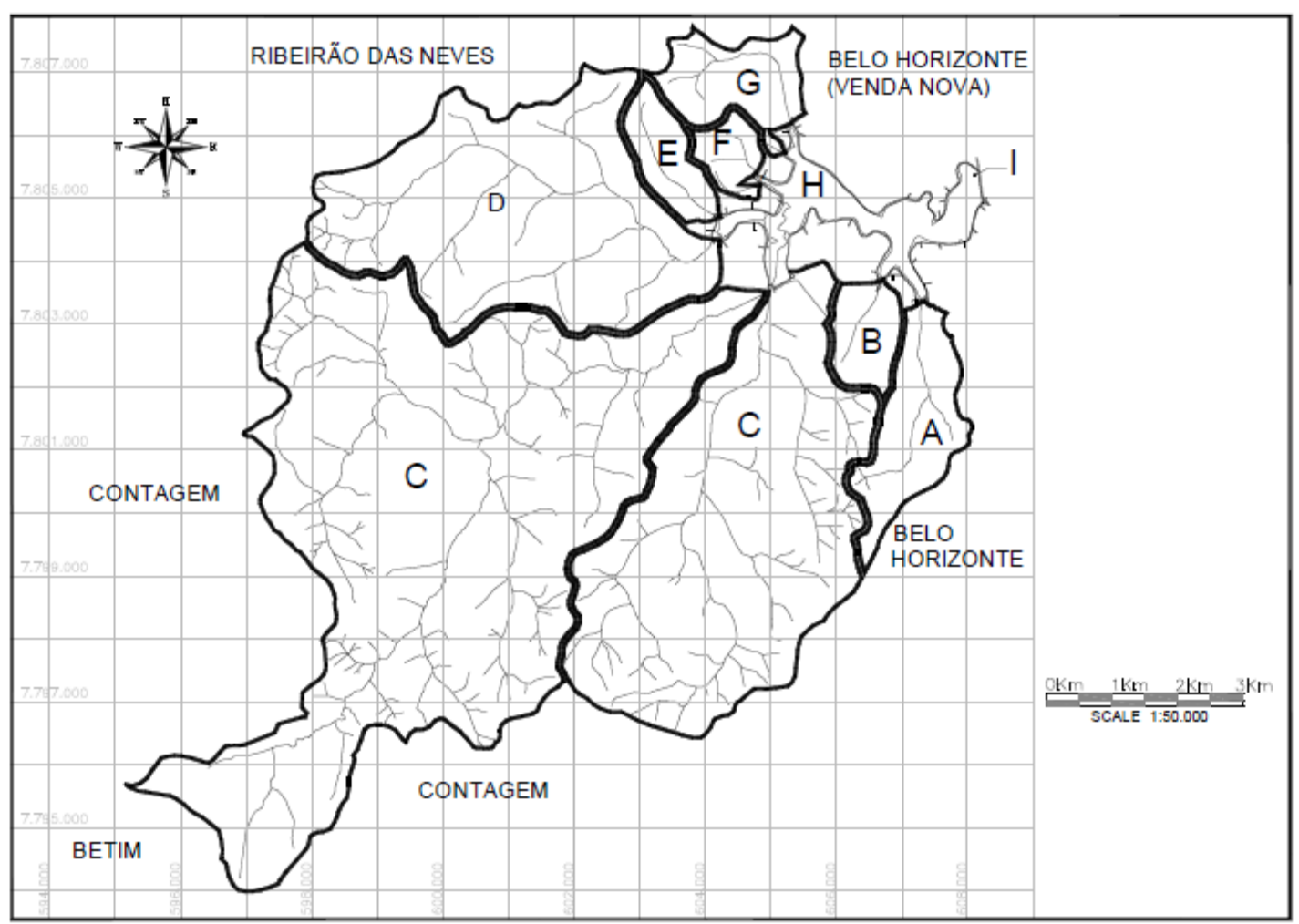

Figura 1. Mapa da bacia hidrográfica da Lagoa da Pampulha com os principais tributários: Córrego Mergulhão (A), Tijuco (B), Ressaca (C), Sarandi (C), Água Suja (D), Baraúnas (E),

Córrego da AABB (F) e Córrego do Céu Azul (G). Mapa em Preto e Branco. 1:50.000.

Fonte: Atlas da qualidade de água do reservatório da Pampulha, Belo Horizonte:

Recóleo.2012, autor: Ricardo Pinto-Coelho.

Revbea, São Paulo, V.10, N 1: 164-179, 2015. 
A partir da década de setenta, o fenômeno de assoreamento da lagoa e da eutrofização de suas águas acelerou chegando, em 1998, ao lamentável quadro de perda de $50 \%$ do seu volume de preservação e de $40 \%$ da área do espelho d'água (PINTO-COELHO, 2012). Além da deterioração da qualidade de suas águas, que apresentam elevados teores de matéria orgânica e baixas concentrações de oxigênio dissolvido, a lagoa também recebe muito lixo. A proliferação de caramujos transmissores da esquistossomose, a proliferação de mosquitos, de plantas aquáticas (macrófitas), waterblooms de cianobactérias criaram gradualmente uma atmosfera de decadência cultural e social (Portal PBH, http://portalpbh.pbh.gov.br, 2012).

A população residente na bacia da Pampulha encontra-se estratificada em diversos níveis socioeconômicos, variando desde o padrão muito baixo até muito alto. Entretanto, a grande maioria da população, cerca de $70 \%$, encontrase nas faixas de renda baixa e muito baixa. A situação social da população da bacia agravou-se pela precariedade do saneamento básico. Cerca de $30 \%$ da área não possui rede de coleta de esgoto e aproximadamente $20 \%$ não é atendida com coleta regular de lixo. Os índices de qualidade de vida urbana IQVU na Pampulha encontra-se, em $90 \%$ da área, abaixo do padrão médio do município (Portal PBH, http://portalpbh.pbh.gov.br, 2012).

Ao longo desses anos, a ocupação desordenada e os escassos investimentos em saneamento básico trouxeram sérias consequências socioambientais para a Bacia da Pampulha. Contribuíram para esse processo especialmente a implantação do Centro Industrial de Contagem (CINCO), da Ceasa/MG, do Aterro Sanitário, das áreas de bota-fora e dos loteamentos residenciais, que geraram uma grande movimentação de terra carreada para a represa (Portal PBH, http://portalpbh.pbh.gov.br). Pinto-Coelho (2012) diz que após o ano 2000, a região da Pampulha passa a receber de volta toda uma série de investimentos em saneamento e paisagismo.

Ás voltas com problemas ambientais que degradam o espelho d'água, a região se encontra em processo de requalificação. A Prefeitura de Belo Horizonte (PBH) e a Companhia de Abastecimento de Água e Esgoto de Minas Gerais (COPASA) prometem recuperar a lagoa, processo previsto inicialmente para o ano de 2014, mas atrasos nas obras, relacionadas a desapropriações de terrenos, impedem a conclusão do projeto que atualmente não tem data para ser finalizado. A $\mathrm{PBH}$ prometeu dragar os sedimentos enquanto que a Copasa se comprometeu a retirar $95 \%$ do esgoto que deságua na lagoa. A expectativa e que ao final do processo de recuperação, as águas estejam dentro do padrão de qualidade classe três, adequada para a prática de esportes náuticos.

Várias também são as ações de mobilização em favor da lagoa da Pampulha, como movimentos promovidos por associações de moradores, Organizações não governamentais (ONG`S), Universidades e demais setores. Entre estes movimentos está o "Pampulha Viva", sucessor do projeto "Pampulha Limpa", dois projetos alvo de avaliação por parte deste trabalho. Movimentos de mobilização e sensibilização da população são de suma Revbea, São Paulo, V.10, N 1: 164-179, 2015. 
importância já que tendem a despertar nas pessoas sentimentos de apropriação do lugar em que vivem o que por sua vez, pode gerar transformações no modo com que estas pessoas lidam com o local. A participação de todos deve ser considerada como uma necessidade para o desenvolvimento social. "A participação é uma aprendizagem. Se conseguimos hoje nos entender, decidir e agir para alcançar alguma coisa, depois seremos capazes de construir e viabilizar soluções para outros problemas" (POLIGNANO et a., 2012, p.37).

\section{Pequeno histórico e características dos Projetos Pampulha Limpa e Pampulha Viva}

\section{Pampulha Limpa}

De acordo com os seus proponentes, o "Pampulha Limpa" (PL) foi um projeto de Educação Ambiental que atuou de 2003 a 2009, visando a sensibilização, conscientização e mobilização de crianças e adultos quanto aos problemas ecológicos da Lagoa da Pampulha, em especial o lixo. Ele fazia parte do programa "Dia Mundial de Limpeza de Rios e Praias", organizado pela ONG "The Ocean Conservancy" em mais de 120 países, envolvendo mais de 40 milhões de voluntários em todo o mundo.

O PL tinha como objetivos principais sensibilizar, conscientizar e mobilizar pessoas quanto aos problemas ambientais da lagoa da Pampulha, como o lixo e seu impacto em ambientes naturais e urbanos, disseminar conceitos e posturas ecológicas corretas na população, promover a coleta de lixo na lagoa a fim de chamar a atenção das pessoas para a quantidade de lixo jogado na mesma, favorecer maior interação entre universitários e estudantes do ensino fundamental, inspirar e estimular atitudes transformadoras, como adoção de nascentes, implantação de coleta seletiva nas escolas e casas, entre outras. Além disso, propunha uma ação comunitária utilizando crianças, que são disseminadoras de informação, para realizar a remoção de resíduos sólidos de nascentes e da orla da lagoa (GUIMARÃES et al., 2005).

A metodologia do PL se baseou na realização de atividades com alunos de quinta a oitava séries do ensino fundamental (entre os 11-14 anos de idade). Em 2003, o projeto mobilizou cerca de 30 monitores voluntários e 200 alunos de quatro escolas localizadas na bacia hidrográfica da Pampulha. $O$ peso total do lixo coletado foi de aproximadamente $400 \mathrm{~kg}$. Em 2004, mobilizou cerca de 90 monitores voluntários e 500 alunos de 12 escolas. O peso total do lixo coletado foi aproximadamente 3,8 vezes maior que no ano anterior, atingindo 1,5 toneladas. Em 2005, o projeto contou com a participação de cerca de 700 estudantes de 14 escolas e 100 universitários voluntários. Foram removidos $829 \mathrm{Kg}$ de resíduos sólidos, sendo que $75 \%$ destes foram retirados da orla da lagoa. A diminuição da quantidade de lixo neste ano foi explicada pelas seguintes razões: (1) o nível de água da lagoa da Pampulha estava maior do que nos anos anteriores. Como resultado disso, houve uma diminuição da área amostrada no entorno da lagoa; (2) o tempo de coleta foi reduzido para 
01h30min, (contra 02h00min horas nos anos anteriores), a fim de diminuir o desgaste físico das crianças e permitir que elas aproveitassem melhor as outras atividades oferecidas durante a confraternização; (3) a lagoa da Pampulha estava sendo mais bem cuidada pela prefeitura e pela população em geral.

Em 2007, 18 escolas participaram da atividade e segundo dados divulgados pelo projeto, foram coletados $920,5 \mathrm{~kg}$ de cerca de 14 mil itens, como plástico, vidro, papel, isopor, metal, madeira e orgânicos. (https://www.ufmg.br, 2012). Em 2009 o PL envolveu mais de 100 universitários voluntários e 1200 estudantes de 22 escolas localizadas na bacia da Pampulha que percorreram 17 pontos da orla para a coleta de resíduos. Após a coleta os resíduos foram classificados e pesados. (Jornal Estado de Minas S/D). Não foram encontradas informações relacionadas ao projeto nos anos de 2006 e 2008.

O PL norteou o desenvolvimento de suas ações da seguinte forma:

- Educação ambiental nas escolas: Palestras educativas foram ministradas abordando temas como a formação da Lagoa da Pampulha, seu processo de degradação, a importância da política dos 3R's (reduzir, reutilizar e reciclar), biodiversidade e os objetivos do PL. Foram realizados concursos de desenhos, a fim de trabalhar o universo lúdico com os alunos, e visitas ao aterro sanitário de Belo Horizonte, para que eles fossem sensibilizados pela quantidade de lixo que é produzido em sua cidade. A avaliação do projeto foi realizada a partir da aplicação de questionário a todos os alunos envolvidos antes e após a execução do PL. Os questionários apresentavam perguntas de múltipla-escolha e abordaram temas como reciclagem, meio ambiente e a Lagoa da Pampulha. Apenas os alunos que participaram de todas as etapas do PL, tiveram seus questionários analisados (não existem dados de quantos alunos tiveram seus questionários avaliados).

- Mutirão de coleta de lixo nas nascentes e orla: A coleta foi realizada sempre no "Dia Mundial de Limpeza de Rios e Praias", terceiro sábado de setembro. O mutirão de coleta de lixo foi realizado em quatro nascentes da Lagoa da Pampulha em 2003, e em quatro nascentes e seis trechos da orla da lagoa, em 2004. Em 2005, o mutirão de coleta de lixo foi realizado em quatro nascentes e quatro trechos da orla da Lagoa. Esta abordagem teve como objetivo vivenciar na prática os problemas urbanos e ecológicos causados pelo lixo da Lagoa da Pampulha. As crianças trabalharam em grupo e foram orientadas pelos monitores a coletar resíduos sólidos, e separá-los em sacos plásticos coloridos, correspondentes às cores da coleta seletiva. Este lixo foi classificado, catalogado e quantificado em fichas padronizadas. Esta atividade ocorreu em aproximadamente duas horas em 2003 e 2004 e 1h30mim em 2005. O lixo que estava em contato com a água foi devidamente retirado pela equipe de profissionais da Secretaria Municipal de Limpeza Urbana (SLU).

O projeto foi avaliado através da aplicação de dois tipos de questionários: um antes de qualquer atividade, e outro depois da realização de 
todas as etapas do projeto, com o objetivo de medir conhecimentos e posturas dos estudantes em relação ao meio ambiente, e outro entre os professores participantes. Além disso, todo o lixo recolhido foi pesado e medido.

Os dados obtidos pelo Pampulha Limpa sobre o aumento da quantidade de resíduos na lagoa, mostraram que apesar das ações desenvolvidas, não houve diminuição da quantidade de resíduos jogados no reservatório. Caso os dados tivessem sido analisados poderiam ter orientado a tomada de outras atitudes (revisão das estratégias e do plano de ação utilizados) para combater o problema.

\section{Pampulha Viva}

Segundo os proponentes, o programa Pampulha Viva (PV) surgiu em 2010 a partir da união de ações de Núcleos coordenados pelo projeto Manuelzão/UFMG (entidades formadas por voluntários que atuam nas micro bacias da Pampulha), empresas e instituições localizadas em microbacias contribuintes e/ou próximas à bacia da Pampulha. Os Núcleos realizam várias atividades de educação ambiental e mobilização social com escolas, empresas e comunidades, e, desde 2006 participam, através do extinto projeto "Pampulha Limpa", do Dia Mundial de Limpeza de Rios e Praias. O programa "Pampulha Limpa" era coordenado em Belo Horizonte pela ONG "The Ocean Conservancy", mas em 2010 passou a ser coordenado pelos Núcleos citados acima e pelo Projeto Manuelzão/UFMG, e com a participação e apoio do Consórcio de Recuperação da Bacia da Pampulha, Astemarp (Associação de Trabalhadores em Materiais Recicláveis da Pampulha), e empresas.

O PV, além de participar do Dia Mundial de Limpeza de Rios e Praias, propõe a realização de atividades antes e após o evento junto a escolas da região da Bacia da Pampulha, trabalhando de forma contínua, temáticas envolvendo os potenciais e atuais problemas ambientais desta bacia. O evento citado acima, além de um momento de sensibilização e simbolismo, e também de mobilização, pois chama a atenção de moradores para a problemática da disposição de dispostos inadequadamente ao longo da bacia.

As informações sobre a metodologia utilizada no Projeto Pampulha Viva e sobre o desenvolvimento das suas ações foram retiradas de documentos como cartas encaminhadas às escolas e aos núcleos, de material de divulgação do projeto (como banners e folders), e, sobretudo de relatos de Daniela Campolina Vieira, Bióloga, coordenadora do projeto, em entrevista concedida no dia 31/10/2012.

As ações de mobilização são desenvolvidas com alunos do $6^{\circ}$ ao $9^{\circ}$ anos do ensino fundamental de escolas públicas da bacia hidrográfica da Pampulha. Segundo Daniela, "as escolas particulares são menos acessíveis", e não demonstram interesse em participar do projeto, por isso as escolas que integram o programa são da rede pública. Em 2010, na primeira edição do

projeto, 14 escolas participaram do projeto com o envolvimento de aproximadamente 450 alunos. Em 2011 foram 19 escolas participantes, com 
cerca de 660 alunos, dezenas de voluntários e mais 35 estagiários do curso técnico em meio ambiente da Escola Técnica CECOM. Em 2012 estiveram presentes no projeto 17 escolas com cerca de 600 alunos e 30 estagiários, alunos da Escola técnica CECOM, e mais aproximadamente 400 pessoas ligadas a empresas participantes, instituições públicas e populares.

O projeto Pampulha Viva estruturou sua metodologia da seguinte forma: todas as escolas envolvidas participam ou já participaram de alguma atividade organizada pelo Núcleo e por isso já conhecem e estão envolvidas em atividades de caráter educativo ligadas ao meio ambiente. São agendadas visitas às escolas, onde a proposta escrita do Programa é apresentada, bem como a definição de datas das outras visitas e atividades.

Em 2010 e 2011, especificamente a partir do mês de março, representantes do projeto visitaram as escolas participantes para a realização de palestras sobre o ciclo da água, bacias hidrográficas, história da Pampulha e aplicação de um pré-questionário para os alunos selecionados, a fim de verificar o conhecimento prévio deles em relação ao tema, e para convidá-los a participar do Dia Mundial de Limpeza de rios e praias, que ocorreria no mês de setembro.

Em 2012, a metodologia descrita acima foi mantida, mas desta vez os professores das escolas também foram incluídos nas atividades. Eles participaram de um curso de formação que os orientava na preparação dos alunos para a atividade. A inserção dos docentes se deu, devido à ideia de que a mesma pudesse incentivar uma maior participação dos alunos.

Em todos os anos, no mês de setembro os alunos selecionados, juntamente com a equipe do PV foram à Lagoa da Pampulha para participar do Dia Mundial de Limpeza de rios e praias. Neste evento, foi proposto aos alunos uma coleta simbólica de resíduos, pela orla da lagoa e por nascentes próximas. Em 2010 foram recolhidos cerca de 1 tonelada e em 2012 aproximadamente 280 toneladas. Este lixo foi separado e pesado com apoio da Companhia de limpeza urbana de Belo Horizonte (SLU). O resíduo coletado fora da lagoa, chamado de lixo seco, foi para a Astemarp, e o lixo recolhido na lagoa, tratado como lixo molhado, foi para 0 aterro sanitário (Daniela Campolina, comunicação pessoal). Não há informação sobre a quantidade de lixo coletado em 2011.

Após a coleta, foi discutido com os alunos sobre a questão do lixo, enfatizando as causas e consequências daqueles resíduos para a lagoa e para a população da bacia. As atividades do PV continuaram nas escolas após o evento "Dia Mundial de Limpeza de Rios e Praias", até o final de cada ano. Os alunos apresentaram o que aprenderam com o Pampulha Viva, resgatando todo o processo. Essa apresentação foi feita através de exposição, seminário ou teatro.

Outra atividade realizada após o evento foi a "Teia da Vida", que se trata de uma intervenção artístico-cultural na qual os alunos interagem acrescentando suas visões e desejos de melhorias na bacia na qual a escola 
se localiza. Ao finalizar o preenchimento da "Teia da Vida", esta fica exposta em outros locais da bacia como escolas, centros de saúde e regionais. A saída da "Teia da Vida" da escola é marcada pelo plantio de uma muda na própria escola ou em suas proximidades.

Para finalizar, houve ainda uma visita a uma área revitalizada, com o intuito de mostrar aos alunos a diferença entre o que viram na lagoa da Pampulha e uma área ambientalmente saudável. A área escolhida foi o Parque Nossa Senhora da Piedade, no bairro Aarão Reis (Belo Horizonte) e pertencente a bacia do Onça, um exemplo de uma conquista da comunidade.

Todas essas atividades foram acompanhadas por representantes do $\mathrm{PV}$, que neste dia, aplicaram também o pós-questionário, para avaliar o que os alunos aprenderam com o projeto. Os grupos de alunos que representaram cada escola receberam um DVD com materiais educativos como apostilas, textos, cartilhas e vídeos. A ideia é que estes alunos sejam referência na escola auxiliando na execução e proposição de ações na mesma.

Em 2012 o Projeto Manuelzão iniciou cursos de capacitação para professores das escolas participantes, sobre Bacias Hidrográficas como Instrumento Pedagógico, mapeando fragilidades e potencialidades existentes nas microbacias. Esta atividade contou com a participação dos Núcleos Manuelzão, Consórcio de Recuperação da Lagoa da Pampulha e a Escola Técnica Cecon-BH.

De acordo com a coordenadora do programa, a avaliação do projeto é positiva, pois melhorou a relação das escolas com o projeto. "Hoje muitas escolas é que nos procuram para participar", disse Daniela. Outro ponto destacado pela entrevistada foi a ampliação da área de trabalho, ou seja, o projeto inclui agora escolas localizadas no município de Contagem, também pertencente à Bacia-foco. Além disso, acredita-se que o fato de os alunos morarem na bacia, contribui para estimular um sentimento de pertencimento dos mesmos em relação à região, tornando-os disseminadores ambientais junto aos amigos e familiares.

Embora haja, por parte da coordenação, uma avaliação positiva do projeto, Daniela também reconhece que mudanças ainda precisam ser feitas. "A ação de coletar resíduos na lagoa deve ser vista apenas como um ato simbólico, que visa apenas chamar atenção da população e do poder público para a situação do reservatório, e não como algo que resolverá o problema do lixo na lagoa. Assim, em nosso entendimento, as ações precisam ser dotadas de caráter participativo: calcado na educação crítica, ganhando assim um cunho reflexivo, reivindicativo e potencialmente transformador da realidade".

Ainda de acordo com a coordenação do projeto, há uma necessidade de se buscar novas parcerias, entre diferentes segmentos sociais e entidades que possam agregar valor aos ideais do projeto. Acredita-se que na edição anterior do Programa, entretanto, não se obteve a ajuda necessária de todos os envolvidos, algumas escolas não liberaram seus professores e muitos estagiários também não se comprometeram como era esperado. 


\section{Discussão}

Ao comparar as propostas de mobilização dos projetos Pampulha Limpa e Pampulha Viva, e sua contribuição para gestão da lagoa da Pampulha, percebe-se que não há grandes diferenças metodológicas entre os dois projetos. O projeto Pampulha Viva manteve basicamente a mesma forma de atuação do seu antecessor, o Pampulha Limpa: ou seja, trabalhar junto a escolas da região com alunos de faixas etárias entre 11 e 16 anos e seus professores, através de palestras e cursos, enfatizando a questão das águas, poluição e histórico da lagoa da Pampulha. Além disso, os dois projetos apresentam como proposta a realização de cursos para formação de monitores e a participação de alunos, professores e voluntários populares no evento "Dia Mundial de Limpeza de rios e praias". As avaliações junto aos alunos são baseadas em pré e pós questionários para mensurar o que os alunos sabem antes e depois do projeto. No caso do PL, além de mobilização, foi considerado como objetivo também, a sensibilização e a conscientização da população. Entretanto sensibilizar e conscientizar são ações subjetivas e, por isso, difíceis de se mensurar (como medir se houve sensibilização e conscientização da população?). No caso deste projeto, é possível avaliar apenas a mobilização da população.

Analisando a participação de pessoas, escolas e outros segmentos sociais, como empresas, percebe-se que o número de participantes nos dois projetos aumentou ano a ano, o que é positivo, pois significa que a aceitação pelo público vem crescendo, e que um número maior de pessoas está sendo inserida no processo de mobilização. Uma participação maior da comunidade pode indicar uma possibilidade maior de sucesso. Entretanto, pela avaliação da quantidade de resíduos coletados todos os anos no evento "Dia Mundial de Limpeza de rios e praias", percebe-se que os dois projetos não apresentaram resultados positivos, ou seja, com o processo de conscientização esperava-se uma diminuição do volume de resíduos no reservatório, e não o seu aumento. Até porque, ambos os projetos afirmaram que este evento, "Dia Mundial de limpeza de Rios e Praias", poderia ser visto apenas como uma ação simbólica, já que não tinha como objetivo a limpeza da lagoa, mas funcionaria como um mecanismo de conscientização sobre a não deposição de lixo na lagoa, o que, no entanto não funcionou.

Contribui para esta situação o fato das ações não alcançarem a totalidade das escolas da bacia, além de não promover a participação de toda a comunidade do entorno da lagoa. Pode-se verificar que o Pampulha Limpa, focou sua atuação em escolas localizadas em Belo Horizonte $(\mathrm{BH})$, próximas à lagoa, enquanto que o Pampulha Viva, embora tenha concentrado suas ações também em $\mathrm{BH}$, teve a ousadia de expandir sua atuação, englobando as escolas do município de Contagem, buscando corrigir uma falha da proposta anterior. Mas em ambos os casos, o número de escolas atingidas pela proposta de mobilização ainda foi muito pequeno para que os resultados pudessem ser realmente significativos. Além disso, trabalhar apenas com as escolas pode não ser a única solução. Toda a comunidade (incluindo aí 
técnicos das prefeituras, de empresas, órgãos de fiscalização, etc.) deveria ser envolvida no processo e para isso, atividades destinadas a este tipo de público deveriam fazer parte da proposta. Vale mencionar novamente, um possível aumento da população residente na bacia, o que poderia aumentar as possibilidades de mais resíduos serem jogados na lagoa.

Como foi mencionado no item 2 deste trabalho (área de estudo), a bacia da Pampulha possui área total de $97 \mathrm{Km}^{2}$, sendo $42 \mathrm{Km}^{2}$ pertencentes a Belo Horizonte e a maior parte, $55 \mathrm{Km}^{2}$, a Contagem. Ou seja, mesmo que se faça um ótimo trabalho na parte da bacia de responsabilidade da prefeitura de Belo Horizonte, as ações ficarão comprometidas e não trarão o efeito desejado para a qualidade da lagoa, pois a porção que se localiza em Contagem tem grande representatividade e, possivelmente contribui de forma mais significativa para a poluição da mesma, tendo em vista o número grande de indústrias instaladas naquela região. Ou seja, temos um problema político a ser resolvido.

Outro fator importante a se destacar nos dois projetos é que as ações têm como público alvo uma pequena parcela dos estudantes, ou seja, aqueles entre 11 e 16 anos. Para que a escola esteja realmente mobilizada seria preciso envolver nas atividades todos os alunos, de todas as faixas etárias, pois assim todos se sentiriam parte do projeto e poderiam agir como multiplicadores. É preciso expandir o acesso ao conhecimento para todos os setores da escola, para que todos participem de forma efetiva do projeto e não apenas como espectadores, pois a verdadeira inserção no processo de educação ambiental pressupõe uma construção coletiva e participativa de todos os atores envolvidos.

Além disso, do modo como vem sendo feita, pode-se dizer que a Educação Ambiental está sendo colocada como algo pontual na vida dos alunos participantes, tratada através de práticas isoladas. Trabalhar os conceitos relacionados ao tema em questão com palestras, oficinas e cursos é de grande importância para contextualizar os participantes. Verificar o conhecimento prévio dos envolvidos é igualmente importante, para que se possa adequar melhor a proposta, ajustando-a ao nível de conhecimento do público-alvo, mas para isso a análise dos dados obtidos através dos questionários aplicados é fundamental.

De acordo com Barbosa e Radicchi (2008, p. 83), "a educação ambiental não pode se limitar a uma simples difusão de conhecimento, mas deve avançar pelo caminho da sensibilidade, que busque a construção de hábitos e atitudes sustentáveis". Esta construção por sua vez, somente será alcançada dentro de uma perspectiva que agregue diferentes áreas do conhecimento, integrando todos os professores, alunos e comunidade.

Para que a Educação Ambiental transforme a vida dos alunos, é preciso abandonar o modelo tradicional de ensino e avançar para uma modalidade de caráter mais realista, na qual a construção do conhecimento se dê através de uma postura transversal, que envolva todas as disciplinas. 
Para que um projeto de Educação Ambiental que contemple uma atitude transversal seja aplicado, primeiramente a escola tem que se tornar parceira da ideia e abrir suas portas a diversas possibilidades, disponibilizando seu corpo docente, dependências, promovendo a participação de todos os alunos e inserindo a Educação Ambiental no currículo escolar, não como uma disciplina formal, mas de forma que cada professor possa trabalhar o tema dentro da sua área de atuação, de acordo com as necessidades locais. Deste modo, cabe ao projeto, no caso o Pampulha Viva, juntamente com a escola, diagnosticar os problemas ambientais locais e de acordo Polignano (2004) "propor aos professores dentro da especificidade de cada área, adequar o tratamento dos conteúdos para contemplar o tema meio ambiente". O mesmo autor exemplifica da seguinte forma:

História: levantar a história dos rios ou córregos;

- Geografia: estudar os cursos de água e o que está ocorrendo com eles;

$>$ Matemática: quantidade de lixo pessoa/dia, volume de água consumida pessoa/dia;

- Português: redação sobre temas ambientais;

$>$ Ciências/Biologia: estudar as causas da mortandade de peixes, as modificações na fauna e flora locais com a eutrofização;

$>$ Educação Física: caminhadas por trilhas ecológicas ou pelas ruas do bairro.

Para que a transversalidade dê frutos, é preciso cooperação entre todos os atores envolvidos: Pampulha Viva, professores, escola, comunidade do entorno e agentes públicos estaduais e municipais, num esforço que possibilite aos envolvidos desempenhar um bom papel diante de suas responsabilidades.

Resolver problemas locais é, segundo Guimarães e Viégas (2004), a melhor maneira de se promover uma estratégia para Educação Ambiental, já que assim a comunidade poderá identificar os problemas que a acometem e participar da elaboração de propostas para resolvê-los. Deste modo, é preciso ter cuidado para que eventos como o "Dia Mundial de Limpeza de Rios e Praias", não sejam maiores que as ações cotidianas locais, pois estas é que realmente produzirão o resultado necessário para a mudança. Sobre isso, Polignano et al (2012, p,93, apud TORO; WERNECK, 1997), disse que "a mobilização social é muitas vezes confundida com manifestações públicas, com a presença das pessoas em uma praça, passeata, concentração. Mas isso não caracteriza uma mobilização". A mobilização ocorre quando um grupo de pessoas, uma comunidade ou uma sociedade decide e age com objetivo comum, buscando, cotidianamente, resultados planejados e estabelecidos por todos. 


\section{Considerações finais}

A questão ambiental nos traz hoje grandes desafios e não pode mais ser deixada para depois. Faz- se necessário a utilização de conhecimentos e práticas educativas que propiciem uma compreensão real e crítica acerca da situação de degradação na qual estamos inseridos atualmente. Nesse sentido cabe destacar que a Educação Ambiental assume cada vez mais uma função transformadora, na qual a co-responsabilização dos indivíduos torna-se um objetivo essencial para promover um novo tipo de desenvolvimento.

A recuperação ambiental da lagoa da Pampulha é de grande importância para a população de Belo Horizonte, tanto pelo seu valor histórico como pela relevância ambiental. Projetos de mobilização como os que foram expostos neste trabalho representam uma boa oportunidade de se inserir a comunidade local no contexto de recuperação ambiental do reservatório. Mas para que isso ocorra será necessária uma ampliação da área de atuação do projeto, que atualmente mantém ações em uma pequena parte da bacia da Pampulha que é muita extensa, já que abrange dois municípios, Belo Horizonte e Contagem. Além disso, é preciso também envolver todos os segmentos da bacia, como escolas, comunidade do entorno e poder público para que sua atuação não se transforme apenas em uma manifestação simbólica. Não existem soluções fáceis e nem imediatas. Mudanças profundas requerem medidas de longo prazo e, portanto, continuidade nas ações dos governantes e da sociedade em geral.

Provavelmente as ações desenvolvidas pelo Pampulha Limpa de 2003 a 2009, e de 2010 até o momento pelo Pampulha Viva contribuíram para que a situação do reservatório não ficasse pior do que vemos hoje, mas ainda há muito a percorrer. É de grande valor o trabalho que foi feito pelo Pampulha Limpa e que vem sendo feito pelo Pampulha Viva, mas é preciso avançar muito mais para que realmente possamos dizer que gerou algum resultado significativo para a lagoa. A proposição de ações de mobilização numa grande área, como por exemplo, a de uma bacia hidrográfica, não é uma tarefa fácil, principalmente pelo fator financeiro. Mas se a intenção é contribuir para a melhoria da qualidade ambiental do reservatório será preciso que o Projeto Pampulha Viva avance nas suas ações.

Trabalhar com escolas pode ser muito vantajoso, pois de acordo com Polignano et al. (2005), "embora nem todas as escolas estejam localizadas nas proximidades de um curso de água, todas se localizam dentro de uma bacia hidrográfica. Assim, pode-se afirmar que todas as atitudes ambientais da escola, dos professores e dos alunos terão uma repercussão direta sobre a bacia". Desta forma a escola possibilita que alunos e os demais envolvidos construam uma identidade, um sentimento de pertencimento junto ao curso de água, contribuindo assim para sua gestão. Mas para isso, é preciso que todos os alunos da escola sejam envolvidos nas ações e não apenas uma parcela como foi feito pelo Pampulha Limpa e vem sendo feito também pelo Pampulha Viva. A inclusão de alguns professores em 2010 pelo Pampulha Viva foi muito 
importante, pois reconheceu-se um equívoco das edições anteriores do projeto. Entretanto, também é necessário que todo o corpo docente da escola atue e que toda comunidade da Bacia da Pampulha seja incluída (moradores, empresas e poder público).

É preciso também que todo o trabalho seja submetido à avaliações periódicas com o objetivo de verificar onde o projeto evoluiu e onde deixou a desejar. Assim, a avaliação funcionará como um indicador da qualidade do projeto. Os questionários utilizados pelo Pampulha Viva podem ser um bom instrumento para esta avaliação, desde que os resultados sejam discutidos e os pontos fortes e fracos das ações sejam identificados. Outra crítica se dá no fato de que os dois projetos, Pampulha Limpa e Pampulha Viva, elencaram em seus objetivos "mobilizar e sensibilizar a população", entretanto sensibilizar é algo muito subjetivo, pois não pode ser medido através das ações propostas, ao contrário da mobilização.

Enfim, espero que este trabalho tenha contribuído para o processo de reflexão acerca das ações de mobilização em prol da Lagoa da Pampulha. Espera-se que em um futuro bem próximo possamos gozar de uma lagoa saudável, que faça jus tanto à sua beleza cênica quanto à sua importância cultural e ambiental para a cidade de Belo Horizonte.

\section{Referências}

BARBOSA, F.; RADICCHI, A.L. Água, saneamento, saúde e educação: A integração a ser construída. In: BARBOSA, F.; BLAKEMORE, H.J. (orgs). Ângulos da água: desafios para integração. Belo Horizonte: Editora UFMG, 2008.

\section{BUSTOS, M.R.L. A educação ambiental sob a ótica da gestão de recursos hídricos. São $2003 . \quad$ Daulo, Disponível em:} http://www.teses.usp.br/teses/disponiveis. Acesso em 22 Jun 2012.

GUIMARÃES, A. Q. et al. Projeto Pampulha Limpa: fazendo educação ambiental em uma grande cidade. Anais do $8^{\circ}$ encontro de extensão da UFMG. Belo Horizonte 03 a 08 de outubro de 2005.

GUIMARÃES, M.; VIÉGAS, A. Crianças e educação ambiental na escola: associação necessária para um mundo melhor?. Revista brasileira de educação ambiental / Rede Brasileira de Educação Ambiental. - n.0 (nov.2004). - Brasília: Rede Brasileira de Educação Ambiental, 2004. 140 p. v.:il. ; $28 \mathrm{~cm}$. Trimestral.

LOUREIRO, C.F.B. Complexidade e dialética: Contribuições à práxis política e emancipatória em educação ambiental; 2006. Disponível em: http://www.cedes.unicamp.br. Acesso: 22 Jun 2012. 
MACHADO, A.T.G.M.; LISBOA, A.H.; GOULART, E.M.A.; POLIGNANO, M.V. (Orgs). Abordagem ecossistêmica da saúde. Belo Horizonte: Instituto Guaicuy, 2012. 200p.

PINTO-COELHO, R.M. (coord.) Atlas da qualidade de água do reservatório da Pampulha. Belo Horizonte: Recóleo, 2012. 56p

POLIGNANO, M.V. Uma viagem ao Projeto Manuelzão e à bacia do Rio das Velhas. Belo Horizonte, Projeto Manuelzão,2004.

POLIGNANO, M.V.; GODINHO, L.; ESTEVES, S.A. et al. Gestão e Agenda Ambiental Escolar: Bacia do Rio das Velhas. Belo Horizonte. 2005

PORTAL PBH- Prefeitura de Belo Horizonte. Pampulha: a síntese da modernidade. Disponível em: http://portalpbh.pbh.gov.br/pbh/ Acesso em: 12 Out 2012

PORTAL UFMG. Informações on line. Disponível em: < www.ufmg.br > Acesso em 18 Nov 2012. Site

SECRETARIA DE MEIO AMBIENTE DE MINAS GERAIS- SEMAD. Educação Ambiental para auto-transfomação, 2012. Disponível em http://www.meioambiente.mg.gov.br/educacao-ambiental. Acesso em 25 Jun 2012

VIEIRA, D.C. Informações sobre o Projeto Pampulha Viva. Belo Horizonte. UFMG, 31 Out. 2012. Informação Verbal 